Hydrobiologia

September 2007, Volume 588, Number 1, Pages 69-

82

http://dx.doi.org/10.1007/s10750-007-0653-2

(c) 2007 Springer. Part of Springer Science+Business

Media

The original publication is available at http://www.springerlink.com
Archimer, archive institutionnelle de l'Ifremer http://www.ifremer.fr/docelec/

\title{
Modelling sand/mud transport and morphodynamics in the Seine river mouth (France): an attempt using a process-based approach
}

\author{
B. Waeles ${ }^{1,2,3}$, P. Le Hir ${ }^{1,{ }^{*}}$, P. Lesueur ${ }^{2}$ and N. Delsinne ${ }^{2}$
}

${ }^{1}$ IFREMER laboratoire, DYNECO/PHYSED Centre de Brest, BP 70, Plouzane, 29280, France

${ }^{2}$ Laboratoire de Morphodynamique Continentale et Côtière, Université de Caen, Caen, France

${ }^{3}$ Present address: Creocean, Zone Technocean, La Rochelle, France

*: Corresponding author : P. Le Hir, email address : plehir@ifremer.fr

\begin{abstract}
:
The mouth of the Seine River estuary (France) has undergone marked morphological evolution over several decades mainly due to engineering works aimed at improving access to Rouen and Le Havre harbours. The intertidal areas are decreasing in size and the lower estuary is accumulating sediment and prograding. In order to understand and better describe the major morphological behaviours of the estuary, a morphodynamic numerical model was developed within the Seine-Aval program. At the end of the 1st part of the research program, a validated fine sediment transport model (3D) was available (Le Hir et al., 2001b). As the present morphological study addresses medium-term issues (a few decades), and because of the need to investigate impacts of local structures or events, we chose to use the so-called "process-based approach" starting from the existing model. First, the existing model was upgraded to account for (suspended) sand transport, and to achieve coupling between morphological changes and sediment transport. Erodability of the sediment accounts for the respective proportions of mud and sand. Simulations starting from an arbitrary surficial sediment cover show that the model is able to reproduce realistic sediment patterns. For example, it is able to change the sediment nature on the intertidal flat near Le Havre from sand to mud. Observed structures of suspended sediment are also reproduced: fine particles mainly follow the turbidity maximum whereas significant concentrations of sand grains in suspension are found where the hydrodynamic stresses are intense. Concerning morphodynamics, simulations with real forcing over one year are discussed. The effect of waves on the bathymetric evolution of the mouth is shown and the sensitivity of morphodynamics to the coupling procedure is tested.
\end{abstract}

Keywords: Morphodynamics - Sediment transport modelling - Sand and mud mixtures 


\section{Introduction}

In natural coastal environments it is common to find several classes of sediments constituting the bed due to different sources of sediments either coming from the continent or from the sea. Sediment distribution can be related to bottom shear stress gradients, and can also vary depending on the relative weight of waves and currents. For this reason the surficial sediment is likely to change with the seasons or even more rapidly, and the sediment column to become stratified. All these features are found in the Seine estuary (e.g. Lesourd et al., 2001). The Seine estuary is supplied with muddy sediment from the upstream river while fine sand is carried in from the sea (Baie de Seine).

The mouth of the Seine River estuary (France) has been undergoing significant morphological changes for several decades mainly due to engineering works aimed at improving access to Rouen and Le Havre harbours (Avoine et al., 1981). One important feature of the area is a progradation of the lower estuary (e.g. Lesourd et al., 2001) forming an ebb-tidal delta at the mouth, in conformity with a net deposition of sand and mud, whose proportions are currently under investigation. Simultaneously, the area of intertidal mudflats is decreasing to the advantage of the schorre. It should be noted that these trends appeared to be declining before the decision was taken to extend Le Havre harbour, which is currently underway.

In order to foresee the future evolution of the Seine lower estuary both in terms of morphology and nature of surficial sediment, a mathematical modelling exercise was planned as an alternative approach to using an existing scale model. It should be noted that the latter (Sogreah, 1997) only concerns morphology, as it is very difficult to simultaneously reproduce sand and mud transport in a distorted physical model.

Over the last 20 years, several morphological mathematical models have been developed based either on sediment transport processes or on expertise and observations of the behaviour of natural systems (e.g. De Vriend et al., 1993). Hybrid models appeared quite recently (e.g. Wang et al., 1998) together with analytical equilibrium models, but most of these approaches do not distinguish the different sediment fractions, or at least do not consider the interactions between cohesive and non-cohesive material. However, these interactions are likely to influence sediment transport patterns because of changes in sediment erodability due to consolidation, as well as variations in settling rates due to flocculation processes. Chesher \& Ockenden (1997) performed numerical simulations on the Mersey estuary (UK). Their results showed that the implementation of sand/mud interactions in the model reduced the transport of both types of sediment because the critical shear stress for erosion of each type is increased by the presence of the other type. One rare example of a morphological model that accounts for sand and mud transport and their interactions is described in Van Ledden \& Wang (2001). Using a 2DV numerical model, these authors investigated the evolution of the sediment distribution in the southern part of the RhineMeuse estuary (Netherlands), where the tide had been reduced after the construction of sluices.

For the present study, which takes place in the frame of the French "Seine aval" scientific programme, we adopted a process-based strategy for the following reasons: first, a process-based 3D model of the estuary (called SiAM-3D) was implemented 
during the previous phase of the programme (Le Hir et al., 2001) and applied to the transport of cohesive sediments and to the formation of the turbidity maximum. Second, our aim was to simulate medium-term evolution, typically one to a few decades, and we hypothesized that both the actual succession of engineering works and the history of real forcings (tide, freshwater discharge, wind and waves) determine the present evolution of the estuary. Consequently it was natural to test the capacity of the existing sediment transport model to simulate this evolution taking into account all these forcings. To reach this target, it was first necessary to implement the transport of sand, then the possible interactions between both types of sediment, and to ensure coupling between variations at the bottom resulting from sediment transport and computed hydrodynamics.

This paper briefly describes the different stages of the SiAM-3D model upgrade: (1) the approach used for modelling sand transport, (2) the characterization of the behaviour of sand/mud mixtures, (3) the modelling strategy for simultaneous sand/mud transport and (4) the morphodynamic update. Then a preliminary application to the Seine estuary is described, and finally the initial results of 1-year-long simulations are commented.

\section{Materials and methods}

\subsection{Modelling sand transport in suspension with erosion/deposition fluxes}

As mentioned above, mud and sand particles behave quite differently, in particular sand grains settle much more rapidly than mud particles. Thus the classical approaches to compute mud or sand transport are fundamentally different. Because of the relatively high settling velocities of sand grains, the transport of sand adjusts very quickly to hydrodynamic variations. Thus empirical formulae of horizontal fluxes that are generally validated under equilibrium conditions can be used to model sand transport. These formulae can describe total (bed load + suspension) sand transport or only the bed load fraction; suspended transport is sometimes computed from concentration and velocity profiles, given an empirical "reference" concentration near the bottom. On the other hand, cohesive sediments can only be transported in suspension and are calculated by solving an advection/diffusion equation for which erosion and deposition fluxes constitute the boundary conditions.

Mixing the two approaches when both classes of sediment are present raises many difficulties. No formulations for equilibrium horizontal fluxes of sediment are applicable when a cohesive fraction is included in the sediment: formulations should depend on the cohesive fraction both in the surficial sediment and in bottom suspensions. On the other hand, some authors have proposed a formulation of erosion fluxes for sand (e.g. Beach \& Sternberg, 1988). After erosion, sand grains are advected by the flow or settle down. This approach, which is generally used for cohesive material, thus appears to be promising when applied to the transport of mixed sediments. However, as sand is transported in suspension, this modelling concept can only reasonably be used for fine sands, which is the case in the lower Seine estuary where the sand mean diameter is $200 \mu \mathrm{m}$ (Lesourd et al., 2001). The first step in our work consisted in checking the ability of such an approach to reproduce empirical horizontal transport functions for sand at equilibrium.

The deposition flux $D$ is always expressed as the product of the settling velocity $W_{s}$ by a "reference" concentration near the bed $C_{\text {bed }}: D=W_{s} \cdot C_{\text {bed }}$ A general expression for the erosion flux $E$ from the literature can be written in the form: $D=E_{0} \cdot T^{\alpha}$ where $E_{o}$ and $\alpha$ are constant, $T=T / T_{e}-1$ is the non-dimensional excess shear stress, and $T_{e}$ is the 
critical shear stress (Shields 1936, in Soulsby, 1997) for resuspension of sand grains. This kind of expression is empirical and erosion fluxes are almost impossible to measure because deposition and erosion fluxes are likely to occur simultaneously. We thus consider $E_{o}$ and $\alpha$ as parameters of the model; they have to be fitted so that computed horizontal sand fluxes are comparable to the measured fluxes under similar hydrodynamic conditions and sediment parameters.

To calculate the deposition flux, the reference concentration $C_{\text {bed }}$ is extrapolated from the concentration in the bottom layer $C_{\mathrm{kmi}}$, assuming the profile concentration in the bottom layer follows the Rouse profile (analytical solution of the advection/diffusion equation at equilibrium for a simple turbulence closure):

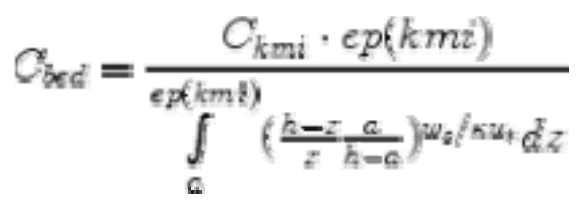

where $e p(k m i)$ is the thickness of the bottom layer, $\mathrm{k}$ is the Von Karman constant and $u$ * is the friction velocity.

$C_{\text {bed }}$ is significantly dependent on the reference height $a$ at which it is expressed: "a" constitutes a third parameter of our fit.

Following such a procedure, horizontal sand fluxes at equilibrium were calculated with the SiAM-1DV code (Le Hir et al., 2001a) and compared with other models in the literature and with total transport formulae which are supposed to fit the data (Fig. 1).

Adjustment of parameters $E_{o}$ and $\alpha$ to the data via the transport formula gives:

$E=0.01 \cdot T^{0.5}$

and the reference height $a=5 \mathrm{~cm}$. The agreement is reasonable considering the variability between the fluxes computed by the formulae or by other 1DV numerical models.

There is no general agreement on the reference height $a$, and results are very dependent on its value. Van Rijn (1984b) suggests $a=0.01 \mathrm{~h}$ when $\mathrm{h}>>$ sand ripple height, which gives $\mathrm{a}=5 \mathrm{~cm}$ for a $5 \mathrm{~m}$ water depth, whereas other authors recommend a reference height related to grain diameter [e.g. $a=2 D$ according to Smith \& McLean (1977)]. To avoid discontinuities in the settling flux from one mesh to its neighbours, we chose a fixed value.

Our fitted power $\alpha(=0.5)$ is weaker than usual: $\alpha$ ranges between 1 (e.g. Beach \& Sternberg, 1988) and 1.5 (Van Rijn, 1984a). This implies reduced dependence of the sediment flux on bottom shear stress, although the range of sand transport rate remains correct: it appears that variations in the latter according to the bottom stress are induced more by increased mixing in the flow than by changes in sand resuspension.

\subsection{Erodability and sedimentation of sand/mud mixtures}

The specific erodability of sand/mud mixtures appears to be the most important process that induces variations in the transport of each sediment class. Torfs (1994a; Mitchener \& Torfs, 1996) tested in a flume the erosive behaviour of homogeneous mixtures made of fine sand $\left(D_{50}=230 \mu \mathrm{m}\right)$ and different muds: kaolinite, montmorillonite or natural muds from the Scheldt (intertidal and subtidal areas). The critical shear stress for erosion has been estimated for different mud contents, keeping a constant density of the mixture. The main trend consists in an increase in the critical shear stress with an 
increase in mud content. The rate of increase depends on the type of mud in the sediment mixture. Panagiotopoulos et al. (1997) evaluated t e for sediment mixtures made of natural mud from the Severn estuary (UK) and two types of sand grains with characteristic diameters $D_{50}$ equal to 152.5 or $215 \mu \mathrm{m}$. Panagiotopoulos experiments show that the increase in $\tau_{e}$ is relatively low when the mass fraction of the mud $F \mathrm{~m}$ is lower than $30 \%$ (corresponding to approximately 11\% of clay); the rate of increase is much higher when $F_{m}$ exceeds 0.3. This feature is observed when the bed shear stress results from a unidirectional current as well as from an oscillatory flow. As the mud fraction increases, the available space between the sand grains decreases. When $F_{\mathrm{m}}$ is lower than about 0.3 , the sand grains remain in contact with each other. When the mud fraction exceeds 0.3 , spaces between sand particles are filled by mud particles which can form a matrix, and, in this case, pivoting is no longer the main mechanism responsible for resuspension of sand grains. Consequently, the whole mixture behaves like a cohesive sediment. As the mud fraction increases, the clay fraction and hence cohesion, both increase.

For very small mud fractions ( $\mathrm{F}_{\mathrm{m}}<5 \%$ ), it appears that the critical shear stress for erosion is lower than that for pure sand (Berlamont \& Torfs, 1995). Torfs et al. (2001) account for this feature in their formulation of the critical shear stress. Either the erosion of mud particles near the water/bed interface occurs earlier or the relatively weak critical shear stress can be attributed to the reduction in inter-granular friction, as mud particles act as a lubricant for the sand grains (Mehta \& Alkhalidi, 2004).

Adding sand to a muddy bed also increases the critical shear stress. This effect is attributed to the increase in the density of the mixture. However, the increase in $\mathrm{T}$ ce is lower when sand grains are added to mud than when mud particles are added to a sandy bottom (Mitchener \& Torfs, 1996)

The sedimentation processes within mixed sand/mud beds remain poorly understood. Laboratory tests have been performed to observe the simultaneous deposition of mud and sand (Torfs (1994b); Torfs et al. (1996); Ockenden \& Delo (1988)). If all the sand and mud settle simultaneously over a short period, two well-sorted layers are formed: sand grains pass through the non-consolidated mud and a sandy layer is formed below the muddy one. For deposition of the same quantities spread out in time (typically $4 \mathrm{~h}$ ), the sand grains are trapped in the consolidating mud when they hit the bed-water interface (Williamson \& Ockenden, 1992).

\subsection{Strategy for simultaneously modelling sand/mud transport}

In order to use the same formalism, both mud and sand are transported in suspension with specific expressions for the erosion and deposition fluxes.

\subsection{Simultaneous transport of mud and sand in the water column}

Following Chesher \& Ockenden (1997) who performed laboratory tests and analysed field data, we assume that sand grains and mud particles can be transported independently in the water column. An advection-dispersion equation is solved for each fraction. The latter is characterized by its own settling velocity which can vary for the mud fraction due to hindering and flocculation processes.

The advection-dispersion equation is written in a three dimensional space with reduced vertical co-ordinates $\sigma$. Due to the high settling velocities of sand grains, the time step for 3D simulations should be very small to ensure stability of the model. In order to avoid time-consuming computations for medium-term simulations ( several years), the sand 
fraction is assumed to be transported in the bottom layer only. But to avoid underestimation of sand transport when turbulence-induced mixing is high or when the water height is low, the horizontal flux is corrected to account for sand grains transported in the other layers. The sand concentration is assumed to follow a Rouse profile whereas the velocity profile is assumed to be logarithmic for the whole water column. The corrective factor is then:

$$
f=\frac{\int_{k} u(z) c(z) d z}{\varepsilon p\left(k_{\mathrm{km}}\right) \cdot U_{k \mathrm{kmi}} \cdot C_{k \mathrm{kmi}}}
$$

where $\mathrm{h}$ is the water depth (between the reference height $a$ and the free surface), $e p(k m i)$ is the thickness of the bottom layer and $U_{k m i}$ is the (mean) flow velocity of this<smiles>[Mg][Mg][Mg][Mg][Mg]</smiles>
layer. ", the so-called "Einstein integral", is numerically calculated at each time step. The integration is computed from the reference height and sand transport between the bottom and this reference height is neglected. Tidal currents in the Seine estuary are strong and the sand is fine $\left(D_{50}=200 \mu \mathrm{m}\right)$, so that transport under the reference height (where the flow velocity is weak) is negligible compared to total suspended transport. This would not be the case in an environment where the flows are weak or the grains are coarse.

\subsection{Deposition fluxes}

Deposition fluxes are expressed independently for each fraction. Deposition of sand grains is function of a reference concentration near the bed $D_{\approx a n d}=H_{₹} \cdot C_{b e d} . C_{\text {bed }}$ is estimated by extrapolating the concentration of the bottom layer, assuming the profile concentration follows the Rouse profile Eq. 1. The deposition flux of mud particles is estimated with the classic law from Krone:

$$
D_{m u d}=W_{m}=C_{m u d} \cdot\left(\mathbf{1}-\tau / \tau_{d}\right)
$$
options. There is no need to extrapolate the mud concentration near the bed because vertical gradients are usually smooth due to small settling velocities.

\subsection{Erosion fluxes}

The erosion fluxes of each sediment fraction depend on the mud content of the surficial layer. This content results from the different erosion and deposition events. Following experiments by Torfs (1995, in Van Ledden 2001) and Panagiotopoulos et al. (1997), and as prescribed by Van Ledden (2001), we distinguish two regimes depending on whether or not the mud fraction $F_{\mathrm{m}}$ of the surficial layer is beyond the critical value $F_{\mathrm{mcr}}$ $(\sim 0.3)$ described in section 2:

- non-cohesive regime $\left(F_{\mathrm{m}}<F_{\mathrm{mcr}}\right)$ : erosion of both particle types is calculated with a formulation adapted for non-cohesive sediment as described in section 1 (the erosion constant for sand $E$ os equals $0.01 \mathrm{~kg} \cdot \mathrm{m}^{-2} \cdot \mathrm{s}^{-1}$, according to (2)) and each class is eroded in proportion to its fraction in the superficial layer:

$$
\begin{array}{ll}
\text { Erocion of sand : } & E_{5}=F_{5} \cdot E_{05} \cdot T^{0.5} \\
\text { Erocion of mud: } & E_{m}^{\prime}=F_{m} \cdot E_{0 \mathrm{la}} \cdot T^{0.5}
\end{array}
$$


where $F_{s}$ and $F_{m}$ are the respective proportions of sand and mud in the surficial layer The critical shear stress increases with the mud fraction from a purely sand bed to the critical mud fraction (Fig. 2) in agreement with the observations of Mitchener and Torfs (1996).

- cohesive regime $\left(F_{\mathrm{m}}>F_{\mathrm{mcr}}\right)$ : the classic law of Partheniades dedicated to cohesive sediments is used for the mixture, that is:

Erosion of sand $E_{\bar{s}}=F_{\mathrm{g}} \cdot E_{0 \mathrm{~m}} \cdot T$

Erosion of mud $E_{m}=F_{m} \cdot E_{\mathrm{O}_{m}} \cdot T$

$E_{o m}$ is the erosion constant for the cohesive regime and was fitted during previous works (Le Hir et al., 2001b); $E_{\text {om }}$ equals $0.002 \mathrm{~kg} \mathrm{~m}^{-2} \mathrm{~s}^{-1}$.

In this case, the critical shear stress still varies with the mud fraction (with a maximum for mixed 50/50 sediment following e.g. Mitchener \& Torfs, 1996) but also depends on the state of consolidation of the sediment (see shaded zone, Fig. 2)

\subsection{The sediment model}

Depending on erosion and deposition fluxes, the respective fractions of sand and mud in the sediment column can vary after each time step of sediment transport, particularly in the surficial layer. The sediment column is discretized in thin layers $(\sim \mathrm{mm})$, in order to be able to reproduce layering patterns, and the thickness of each layer is calculated differently depending on whether the layer is more sandy or muddy. For a sandy layer ( $F$ $\mathrm{m}<F \mathrm{mcr}$ ), the volumetric fraction of sand is fixed (corresponding to a given arrangement of grains) and a varying quantity of mud fills the spaces between the grains. The thickness of muddy layers is likely to vary depending on consolidation processes. The latter are not explicitly accounted for at the present stage of our model, and an intermediate concentration of the muddy fraction is assumed together with a rather low value for the critical shear stress for deposition $T_{d}$ (this prevents the constitution of consolidated sediment in the model while, in nature, freshly deposited materials can be easily eroded by the flow).

When sediment is deposited it is included in the existing surficial layer or it constitutes a new layer, depending on its own mud content and the mud content of the surficial layer. The model procedure tries to follow the observations of several authors (see $\S 2$ ): sand grains settling on a muddy bed are likely to settle through non-consolidated or partially consolidated mud. If the surficial muddy layer is well consolidated, sand grains form a new sandy layer. Different cases are considered, see table below (as consolidation is not explicitly accounted for in this study, settling sand grains are always mixed with the surficial layer made of intermediate concentrated muddy):

\begin{tabular}{|l|l|l|l|l|l|l|}
\hline $\begin{array}{l}\text { Settling } \\
\text { material }\end{array}$ & \multicolumn{3}{l|}{ Sandy } & \multicolumn{2}{l|}{ Muddy } \\
\hline $\begin{array}{l}\text { Surficial layer } \\
\text { structure }\end{array}$ & Sandy & Muddy & $\begin{array}{l}\text { consolidated } \\
\text { muddy }\end{array}$ & sandy & Muddy & $\begin{array}{l}\text { consolidated } \\
\text { muddy }\end{array}$ \\
\hline Mixing & Yes & Yes & No & No & Yes & No \\
\hline
\end{tabular}

\subsection{A 3D morphological model}

The hydrodynamic model used in this work is the SiAM-3D code (Cugier \& Le Hir, 2002). It is characterized by a separation between external and internal modes: water surface 
variations are solved using a $2 \mathrm{DH}$ model to save computation time. Turbulence closure is based on a mixing length model that accounts for turbulence damping by density gradients. SiAM-3D has been modified for this study: a sigma coordinates version was developed to better reproduce the flow in the bottom layer where the sand grains are transported.

The bathymetric update results directly from the balance between deposition and erosion of mud and sand. It is computed at each time step of the suspended matter transport, and thus no specific morphological time step is required.

\section{Results: first application to the Seine estuary}

\subsection{Study area}

The Seine estuary is located in north-west France; it is $150 \mathrm{~km}$ long and about $10 \mathrm{~km}$ wide at the mouth (Fig. 3). The mouth is characterized by a central navigation channel between two submersible dykes designed to reinforce the ebb currents. The area is macrotidal with a tidal range reaching more than $7 \mathrm{~m}$ in spring. The average flow of the Seine river is $450 \mathrm{~m} 3 \cdot \mathrm{s}-1$ and ranges from $100 \mathrm{~m} 3 \cdot \mathrm{s}-1$ in low river discharge conditions in summer to 2,000 m3.s-1 in winter. A turbidity maximum is observed in the lower section of the estuary, between Tancarville (Fig. 3) at low river flow and the estuary mouth at high river discharge. Waves in the Seine estuary are usually generated locally, mainly in the Baie de Seine west of the estuary (Silva Jacinto, 2001). Swell waves from the open sea are rare as they are strongly refracted when they reach the Seine mouth. Local wind wave direction and height are closely related to the direction and length of the fetch. For winds blowing from South-East to North, the fetch is too short to generate high waves in the estuary. The most frequent waves propagate from South-West and their typical height is between $1 \mathrm{~m}$ and $2 \mathrm{~m}$. The biggest waves are generated by westerly winds and can exceed $4 \mathrm{~m}$ height. They do not often occur but when they do, they cause significant erosion.

\subsection{Model implementation}

The size of the cells ranges from $4 \mathrm{~km}$ at the open sea boundary to approximately $200 \mathrm{~m}$ upstream of the mouth where the gradients of velocity and concentration are higher, and require a fine description to reproduce small scale processes related to the gradients. According to the vertical sigma coordinates, the water column is discretized in 10 layers of equal thickness (10\% of the water depth). The time step to calculate the flow structure and the suspended sediment transport is about $200 \mathrm{~s}$. Only one size of sand grains is considered with a characteristic diameter equal to $200 \mu \mathrm{m}$. Wave heights and resulting orbital velocities and shear stresses in the study area are calculated by means of the Hiswa code (Silva Jacinto, 2001); the latter model is forced at the open boundaries by waves whose height and period are computed using parametric formulations based on real wind velocity and direction and fetch characteristics in the Baie de Seine. In fact, preliminary simulations were performed with the initial bathymetry to provide a database of wave orbital velocity distributions for typical wave and water level configurations (Le Hir et al., 2001b). During the morphodynamic runs, the distribution of wave orbital velocity is deduced from the previous database by interpolation of wave height and water level. To account for the bathymetric update, orbital velocities (previously computed according to the initial bathymetry by Hiswa) are modified according to the 
water depth variations due to the bathymetric evolution between the current bathymetry and the initial bathymetry, assuming that wave heights are not changed. On the intertidal flats, wave height is limited to a fraction of the water depth in order to represent the dissipation of wave energy induced by bed friction or by breaking: this fraction was estimated at 0.3, extrapolating from an existing measurement for Le Havre mudflats (Le Hir et al., 2001b). The total bed shear stress capable of eroding the sediment is computed as the sum of the shear stress induced by the current and the shear stress induced by waves.

At the upstream boundary, no sand supply is prescribed because a dam prevents it. During the flood, a sand flux in equilibrium with current velocity is imposed at the open sea boundary. As for the muddy particles, a flux is imposed at the upstream boundary as a function of the Seine river discharge; at the open sea boundary, a constant concentration is imposed.

\subsection{Bottom shear stress distribution}

Figure 4 shows the highest bottom shear stresses simulated over a spring tide period. Maximum tidal shear stresses (Fig. 4a) mainly occur in the navigation channel and secondarily in the channels located north and south of the submersible dikes. In the navigation channel, maximum flow velocities are analogous during ebb and flood, but in the northern and southern channels, the maximum values of bottom shear stress result from flood currents.

Waves can strongly enhance the bed shear stress at the mouth of the estuary on each side of the navigation channel as shown in Fig. 4b. The corresponding simulation was performed for typical stormy conditions: waves are generated by a $20 \mathrm{~m} \cdot \mathrm{s}^{-1}$ wind blowing from the South-West.

In the following section, simulations are described with real forcings (tide, wind and Seine river discharge) that correspond to the year 2001. These forcings are plotted in Fig. 5.

\subsection{Surficial distribution of mud and sand}

To test the model's ability to reproduce observed sediment patterns, simulations were performed starting from an arbitrary bed made of $2 \mathrm{~m}$ of sand everywhere, except for the upstream estuary where a stock of easily erodable mud is imposed. After several tides, the model reproduces the main structures of the sediment cover observed in the estuary. The Northern mudflat begins to form and mud is accumulated in Le Havre harbour. The navigation channel remains covered by sand. In high river discharge conditions, the upstream mud supply increases (Brenon \& Le Hir (1999); Guézennec et al. (1999)) and a large part of the estuary is covered by mud as can be seen in Fig. $6 a$. The sediment covering varies considerably over one tidal period; deposition of mud is favoured during high and low water tidal slacks when the current is weak enough to allow deposition. When flow velocities are high, fine sediment can deposit and subsist only in sheltered areas such as the northern mudflat; this is illustrated by the minimum values of the mud content in the surficial layers (Fig. $6 a$ and b).

\subsection{Sand and mud in suspension}

Figure 7 shows concentrations of suspended matter for a simulation without waves: tidally-averaged concentrations in the bottom layer are presented for spring tide 
conditions and for two typical river regimes. Significant quantities of mud and sand in suspension do not occur at the same places. High concentrations of sand grains in the water column are found where the tidal currents are maximal, as is the case in the navigation channel and particularly at its entrance to the open sea. These concentrations are not linked to variations in river discharge. On the other hand, mud suspensions are characterized by a turbidity maximum which shifts upstream under low water discharge conditions (Brenon \& Le Hir, 1999).

\subsection{Medium scale morphodynamics (time scale: one year)}

The bathymetric evolution of the Seine estuary was simulated for a 1-year period (2001). When hydrodynamic forcing only comprises tidal currents, the banks at the mouth of the estuary undergo global accretion and prograding (Fig. 8a). In addition, the northern mudflat accumulates sediment, especially in its western part near the high water level.

The effect of waves is significant on the banks at the mouth especially on the northern banks, which are eroded on their south-west side, whereas deposition occurs on the opposite side (north-east). This behaviour might be due to the direction of waves in the estuary. The most frequent direction for waves is south-west. When the waves reach a bank, the wave-induced shear stresses increase as the water depth decreases. The bottom shear stress then decreases on the north-east side of the bank where the water depth increases, thus resulting in deposition. The morphological evolution of the banks can be attributed to this variation in the gradient of shear stress induced by waves.

In addition, net deposition of sediment can be observed in the navigation channel entrance (close to the open sea) and upstream from the Normandy Bridge, these locations being the main dredging sites in the area (Sogreah, 1997).

\section{Discussion}

The model results show different suspension patterns for sand and mud. Due to relatively strong settling velocities, sand grains are only resuspended locally and concentrations of sand depend to a great extent on the local surficial sediment covering. In fact, areas of high concentrations of suspended sand are usually characterized by a sandy bed. The navigation channel and the southern part of the mouth of the estuary are mainly covered by sand (Fig. 6) and are subject to large amounts of suspended sand. On the other hand, mud particles in suspension can accumulate far from where they were eroded; for example, the turbidity maximum under low river discharge conditions (Fig. 7b) is located in the navigation channel where the bed is almost exclusively sandy. It should be noted that the model presented here does not account for consolidation processes explicitly, assuming that a muddy bed is moderately and steadily consolidated. Enhanced resuspension of freshly deposited sediment is simulated simply by preventing their deposition when the bottom shear stress exceeds a critical value (the critical shear stress for deposition). In fact, compaction modifies the erodability of the sediment, and simulations with sediment compaction are currently underway. As it results from successive periods of deposition and erosion, the resistance of a surficial layer to the bottom shear stress can vary. Variations in erodability, especially of muddy layers, are likely to play a significant role in sediment transport throughout the estuary. In order to show the role of morphological coupling (feedback from bathymetric changes induced by sediment transport on waves and currents), a simulation was performed with 
real forcing (tide + waves) but with no morphological update in the computation of hydrodynamics. In this case, the morphological evolution represents a sum of deposition/erosion rates, with no coupling between hydrodynamics and sediment transport. Figure $8 \mathrm{~b}$ and $\mathrm{c}$ show that the bathymetry evolution is sensitive to the morphodynamic update, especially in areas where waves have significant effects, as shown in. As an example, the erosion of the western edge of the northern bank is stronger when the bathymetry is not updated. When erosion occurs, the bed level is shifted downwards and the water depth increases for a given water level. If hydrodynamics are then computed with the new (enlarged) water depth, the wave induced erosion is likely to decrease. This sensitivity is rather high on the Ratier Bank (south-west of the entrance to the navigation channel). Without morphodynamic coupling, it exhibits a similar trend as the northern banks: its south-west edge is eroded while net deposition occurs on the opposite side. Its bathymetric evolution is inverted when the coupling is effective and is nearly the same as without waves (Fig. 8a). In simulations of longer periods, the bathymetric evolution could be more significant and the coupling effects have to be accounted for.

\section{Conclusion}

A process-based model was developed to understand sediment transport and morphodynamic behaviours in the Seine estuary. The model accounts for processes related to sand/mud interactions. The evolution of the sediment cover simulated by the model is qualitatively correct. Starting from an arbitrary bed, the model is able to reproduce observed sediment patterns like the northern mudflat near Le Havre harbour. The model shows significant variations in the mud content in the surficial layer ( $2 \mathrm{~mm}$ ) during a tidal period. These features now have to be compared with data to evaluate the model's ability to transport simultaneously cohesive and non-cohesive sediment. A comparison between "numerical sediment cores" and physical sediment cores at the same site should be made to test the model's ability to reproduce observed layering. A more realistic initial condition for the bed content of mud and sand should be tested because it determines the local sediment supply.

The morphodynamic evolution simulated with SiAM-3D for a period of one year is significant at the mouth of the estuary, especially on the banks where wave have strong effects. The morphodynamic behaviour of the model appears to be qualitatively correct. However, longer simulations have to be run (at least two years) to compare the results with data because the time step for bathymetric data is approximately one year; and several months are required to collect one data set. It is intended to simulate the morphological evolution for the last decade when large engineering works induced strong morphodynamic behaviours.

\section{Acknowledgements}

This work was carried out in the framework of the Seine-Aval Scientific Programme coordinated by the Regional Council of Haute Normandie. Hydrographic data were provided by Rouen Port Authority. 


\section{References}

Avoine, J., G. P. Allen, M Nichols., J. C. Salomon \& C. Larsonneur, 1981. Suspended sediment transport in the Seine estuary, France: effect of man-made modifications on estuary-shelf sedimentology. Marine Geology 40: 119-137.

CrossRef

Brenon, I. \& P. Le Hir, 1999. Modelling the turbidity maximum in the Seine estuary (France): identification of formation processes. Estuarine, coastal and shelf science 49: 525-544.

CrossRef ChemPort

Beach, R. A. \& R. W. Sternberg, 1988. Suspended sediment transport in the surf zone: response to cross-shore infragravity motion. Marine Geology 80: 671-679.

CrossRef

Berlamont, J. \& H. Torfs, 1995. Modelling (partly) cohesive sediment transport in sewer systems. International Conference on Sewer Solids-Characteristics, movement, effects and control, 5-8 September, Dundee (UK).

Chesher, T. J. \& M. C. Ockenden, 1997. Numerical modelling of mud and sand mixtures. Cohesive sediments In Burt, N., R. Parker \& J. Watts (eds), John Wiley \& Sons, Newyork, NY, USA, 395-406.

Cugier, P. \& P. Le Hir, 2002. Development of a 3D Hydrodynamic model for Coastal Ecosystem Modelling. Application to the plume of the Seine River (France). Estuarine, Coastal and Shelf Science, 55: 673-695.

CrossRef

Davies, A. G., L. C. Van Rijn, J. S. Damgaard, J. Van de Graff \& J. S. Ribberink, 2002. Intercomparison of research and practical sand transport models. Journal of Coastal Engineering, 46: 1-23.

CrossRef

De Vriend, H. J., M. Capobianco, B. Latteux, T. Chesher \& M. J. F. Stive, 1993. LongTerm Modelling of Coastal Morphology: A Review. In de Vriend, H. J. (ed.), Coastal Morphodynamics: Processes and Modelling. Coastal Engineering 21: 225-269.

Guézennec, L., R. Lafite, J. P. Dupont, R. Meyer \& D. Boust, 1999. Hydrodynamic of suspended particulate matter in the Tidal Freshwater Zone of a macrotidal estuary (The Seine estuary, France). Estuaries, 22(3A): 717-727.

CrossRef

Le Hir, P., P. Bassoulet \& H. Jestin, 2001a. Application of the continuous modeling concept to simulate high-concentration suspended sediment in a macrotidal estuary. In McAnally, W. H. \& A. J. Mehta (eds), Coastal and Estuarine Fine Sediment Processes, Elsevier, 229-247. 
Le Hir, P., A. Ficht, R. Silva Jacinto, P. Lesueur, J. P. Dupont, R. Lafite, I. Brenon, B. Thouvenin \& P. Cugier, 2001b Fine Sediment Transport and Accumulations at the Mouth of the Seine Estuary (France). Estuaries 24(6B): 950-963.

CrossRef

Lesourd, S., P. Lesueur, J. C. Brun-Cottan, J. P. Auffret, N. Poupinet \& B. Laignel, 2001. Morphosedimentary evolution of a macrotidal estuary subjected to human impact ; the example of the Seine (France). Estuaries, 24(6b): 940-949.

CrossRef ChemPort

Mehta, A. J. \& M. Alkhalidi, 2004. Some Observations on the Role of Mud in Modulating Sand Transport. 2004 Ocean Science Meeting, Portland.

Mitchener, H. \& H. Torfs, 1996. Erosion of mud/sand mixtures. Coastal Engineering 29: $1-25$.

CrossRef

Ockenden, M. C. \& H. Delo, 1988. Consolidation and erosion of estuarine mud and sand mixtures. HR Wallingford Report No. SR 149.

Panagiotopoulos, I., G. Voulgaris \& M. B. Collins, 1997. The influence of clay on the threshold of movement of fine sandy beds. Coastal Engineering 32: 19-43.

CrossRef

Silva Jacinto, R., 2001. Action des vagues sur les estrans et vasières. Application à l'estuaire de la Seine. Thèse de l'université de Rouen, 231 pp.

Smith, J. D. \& S. R. McLean, 1977. Spatially averaged flow over a wavy surface. Journal of Geophysical Research 82: 1735-1746.

CrossRef

SOGREAH, 1997. Port 2000, Etude sédimentologique sur modèle physique, Rapport de synthèse, $45 \mathrm{pp}$.

Soulsby, R. L., 1997. Dynamics of Marine Sands. Thomas, Telford publications.

Torfs, H., 1994a. Erosion of mixed cohesive/non cohesive sediments in uniform flow. In 4th Nearshore and Estuarine Cohesive Sediment Transport Conference INTERCOH'94, Wallingford, Paper No. 20.

Torfs, H., 1994b. Erosion of layered sand-mud beds in uniform flow. In Proceedings of the 24th International Conference on Coastal Engineering, Kobe, 3360-3368.

Torfs, H., 1995. Erosion of sand/mud mixtures. Katholieke Universiteit Leuven, faculteit der Toegepaste Wetenschappen, Departement Burgelijke Bouwkunde, Laboratorium voor Hydraulica, Belgium.

Torfs, H., H. Williamson, H. Huysentruyt et, \& E. Toorman, 1996. Settling and consolidation of mud/sand mixtures. Coastal Engineering 29: 27-45.

CrossRef 
Torfs, H., J. Jiang \& A. J. Mehta, 2001. Assessment of the erodibility of fine/coarse sediment mixtures. In McAnally, W. H. \& A. J. Mehta (eds), Coastal and Estuarine Sediment Processes. Elsevier Science B.V.

Van Ledden, M., 2001. Modelling of sand-mud mixtures. Part II: A process-based sandmud model. WL | DELFT HYDRAULICS (Z2840).

Van Ledden, M. \& Z. B. Wang, 2001. Sand-mud morphodynamics in an estuary In: Proceedings 2nd Symposium on River, Coastal and Estuarine Morphodynamics Conference, Obihiro, Japan, 505-514.

Van Rijn, L. C., 1984a. Sediment pick-up functions. Journal of Hydraulic Engineering 110(10): 1494-1502.

Van Rijn, L. C., 1984b. Sediment transport part 1: bed load transport. Journal of Hydraulic Engineering 110(10): 1613-1641.

CrossRef

Wang, Z. B., Karssen, B., Fokkink, R. J. \& Langerak, A., 1998. A dynamical/empirical model for long-term morphological development of estuaries. In Dronkers, J. \& M. B. A. M. Scheffers (eds), Physics of Estuaries and Coastal Seas, Balkema, Rotterdam.

Williamson, H. J. \& Ockenden, M. C., 1992. Tidal Transport of Mud/Sand Mixtures, Laboratory Tests. HR Wallingford, Report SR 286.

\section{Figures}

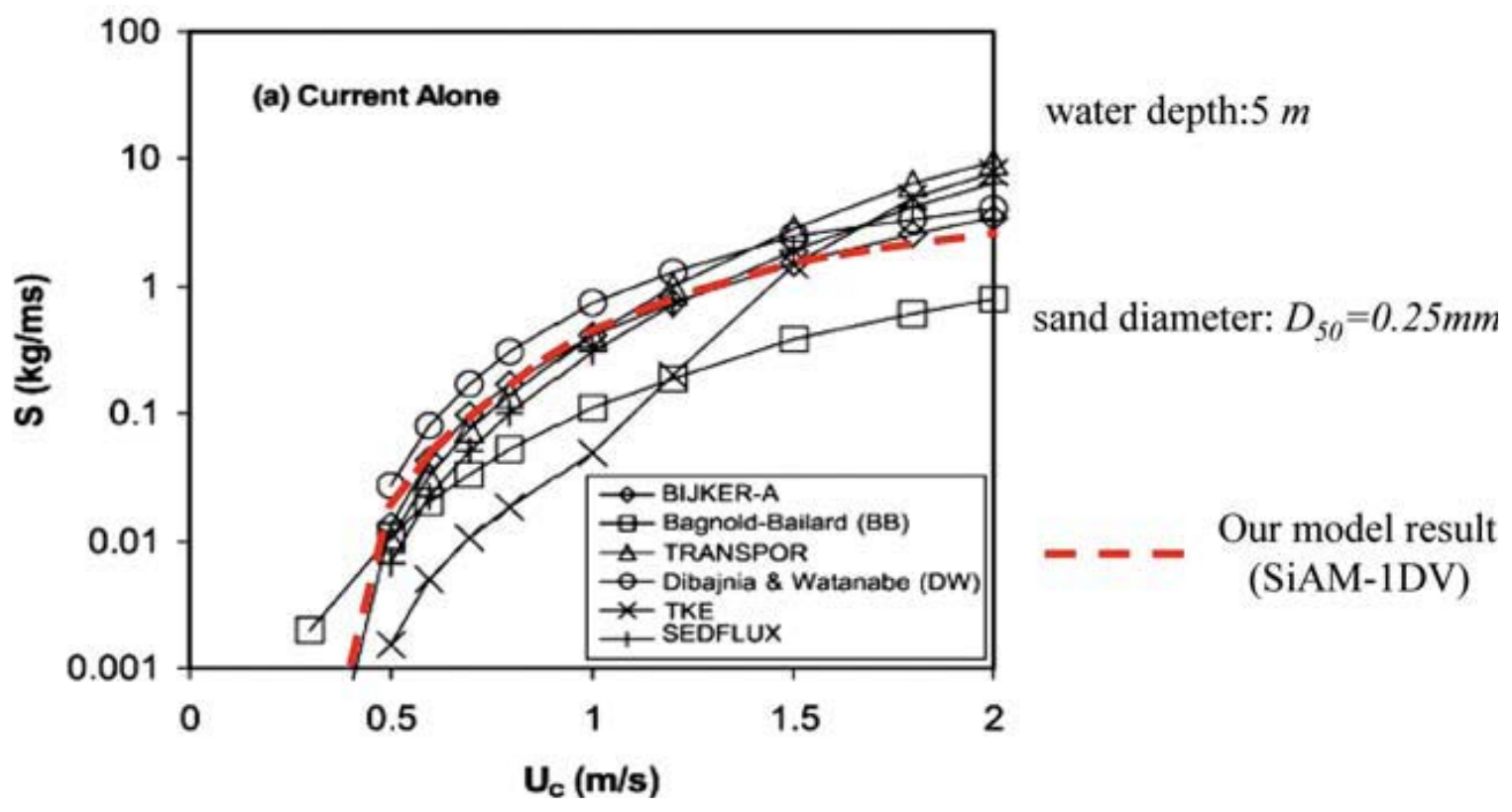

Fig. 1 Variations in equilibrium transport (sand horizontal fluxes) with the depth-averaged flow velocity for total transport formula (Bijker, Bagnold-Bailard, Dibajna \& Watanabe), or calculated by published 1DV models (TRANSPOR, TKE, SEDFLUX) and by our 
procedure (SiAM-1DV). The water depth is $5 \mathrm{~m}$ and the diameter of the sand grains in suspension ranges from $170 \mu \mathrm{m}$ for $U \quad c<0.5 \mathrm{~m} \mathrm{~s}-1$ to $250 \mu \mathrm{m}$ for $U \quad c=2 \mathrm{~m} \mathrm{~s}-1$. Results cited from the literature are those of Davies et al., 2002.

\section{non-cohesive}

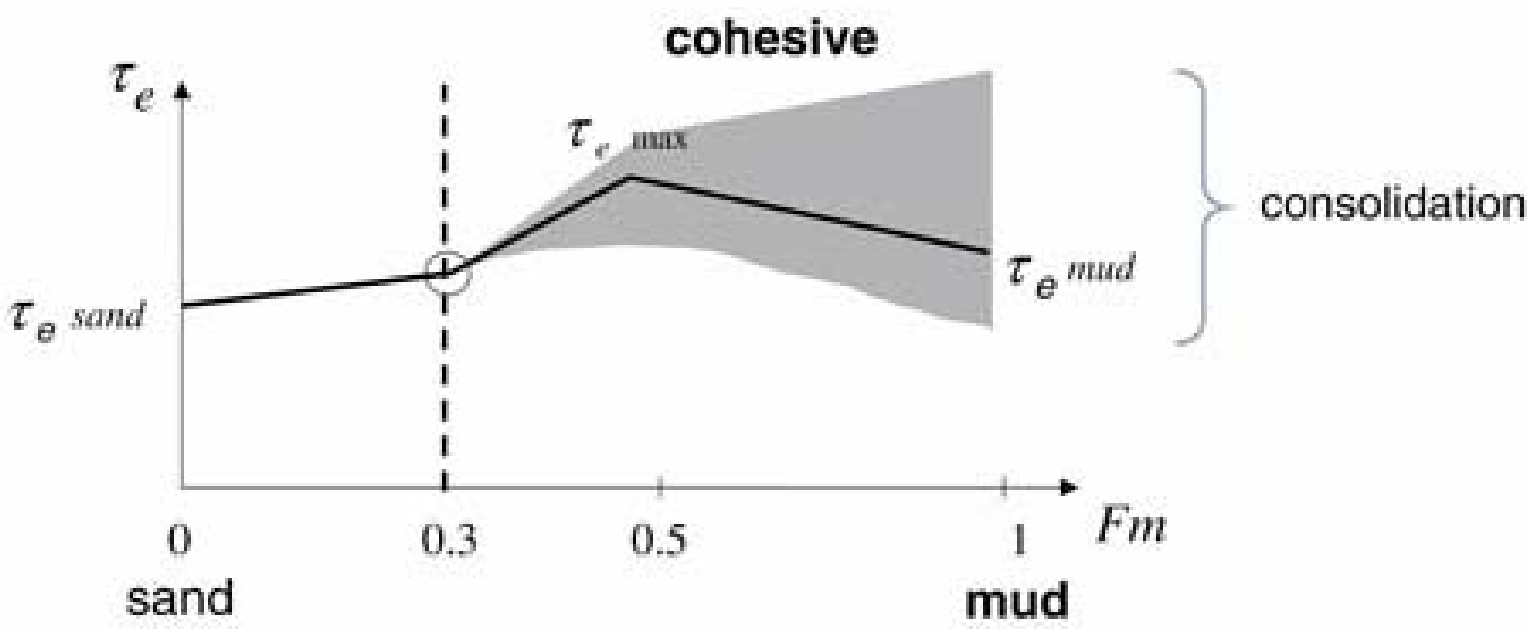

Fig. 2 Sketch of variation in the critical shear stress with variations in mud content $F \mathrm{~m}$ . The shaded zone representing the cohesive regime, means that the critical shear stress of the sediment depends both on the mud content and on the concentration of the mud itself (in the volume not occupied by the sand grains) 

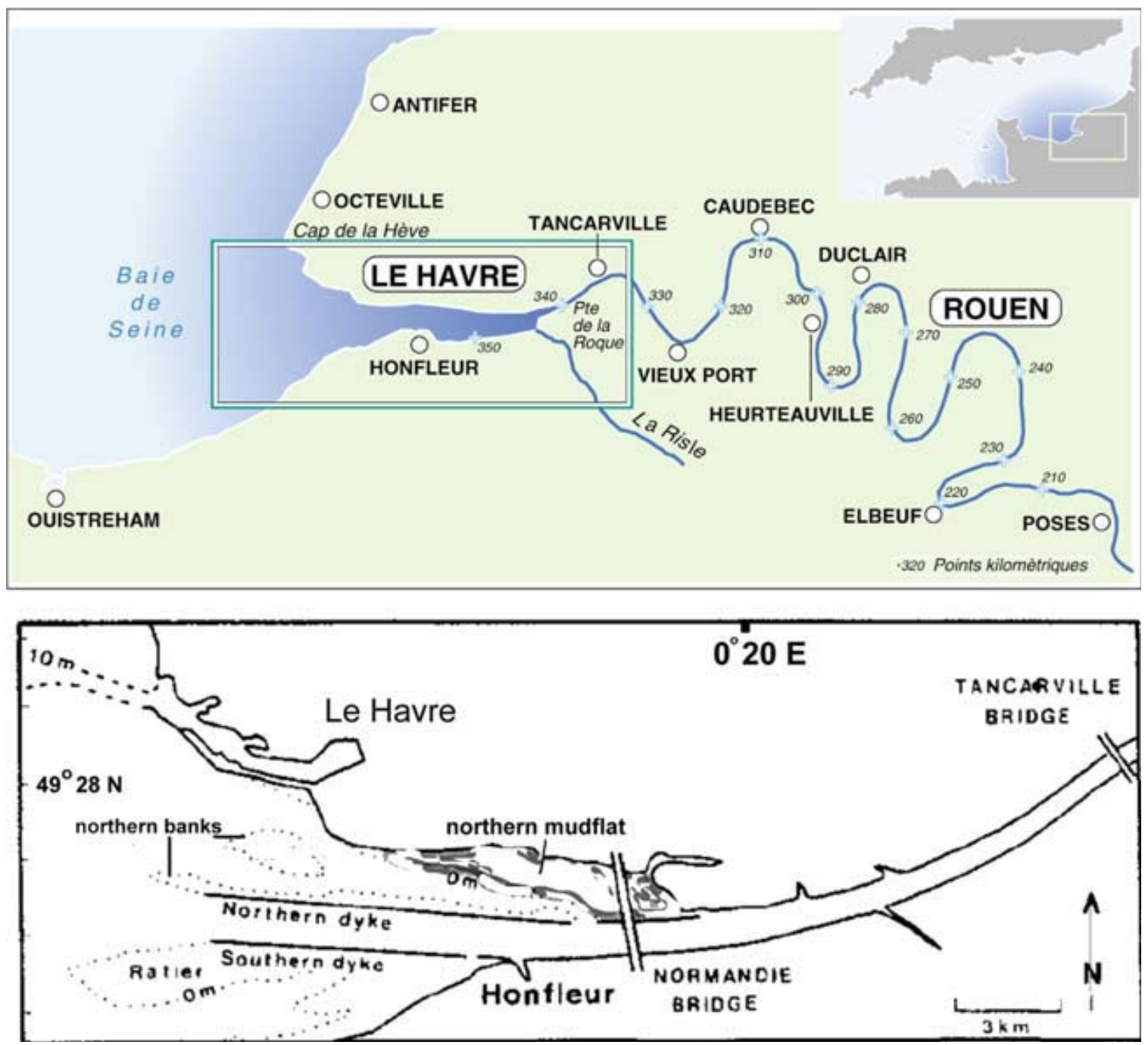

Fig. 3 Location of the Seine estuary and the eastern Baie de Seine with details of the mouth of the Seine estuary 


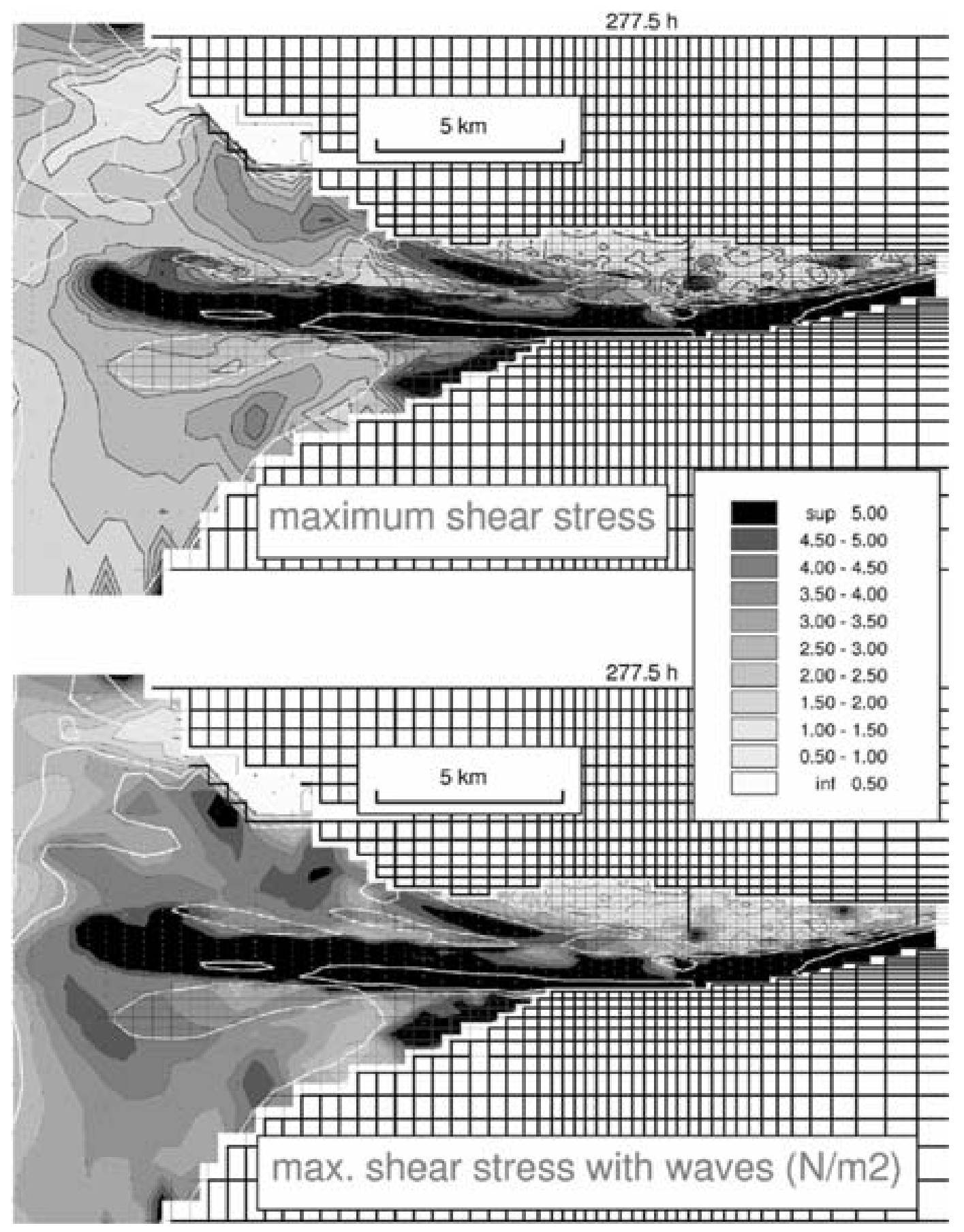

Fig. 4 Distribution of the maximum (over a tidal period) bottom shear stress on the Seine estuary in spring tide conditions (a) tide only (b) tide + wind and waves (wind is constant during the tidal period: it blows from South-West at $20 \mathrm{~m} \mathrm{~s}-1$ ). 

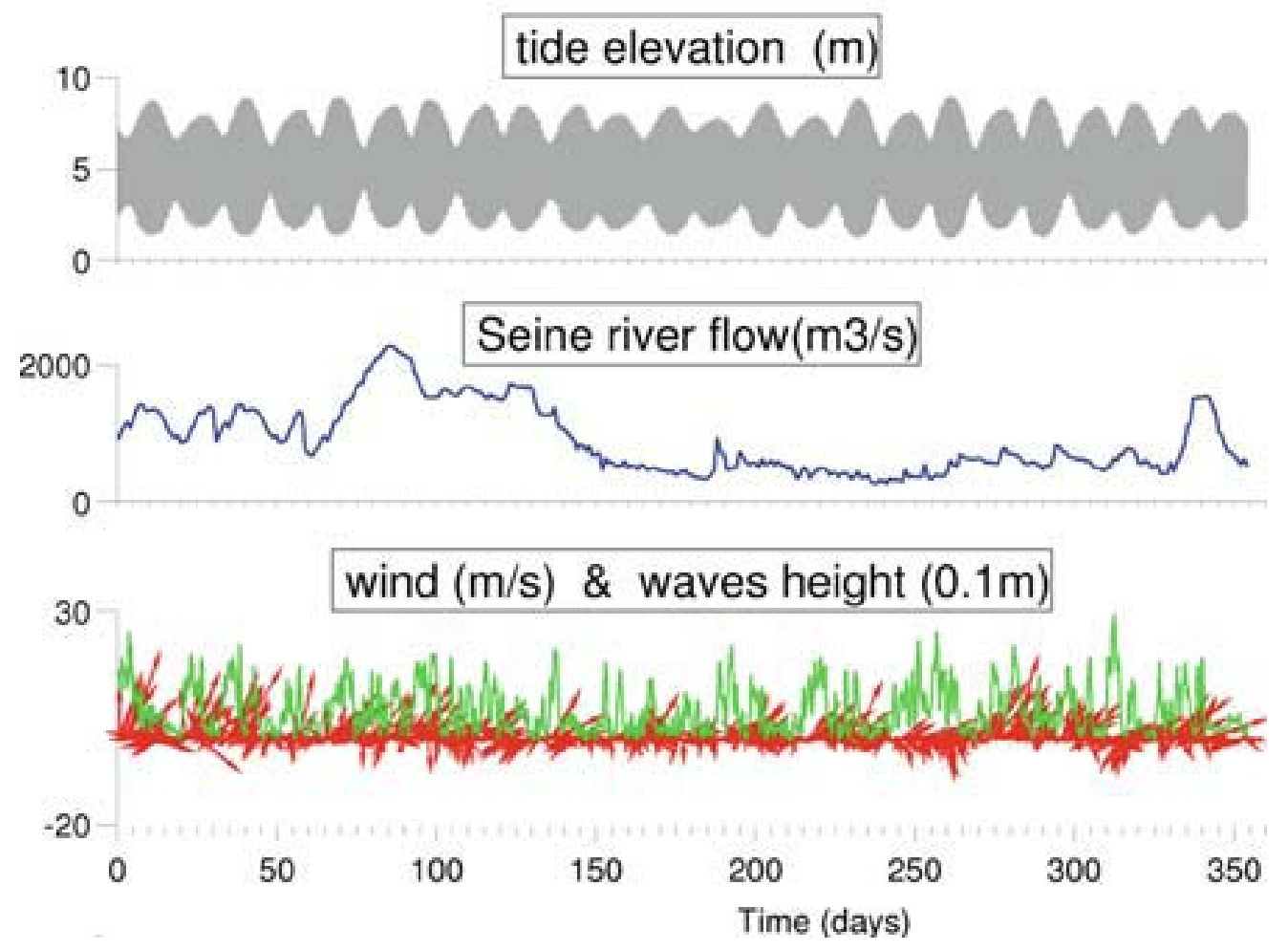

Fig. 5 Tide elevation; Seine River flow; wind intensity + direction (in red) and wave height during the year 2001 (variables simulated with SiAM-3D). 
(a)

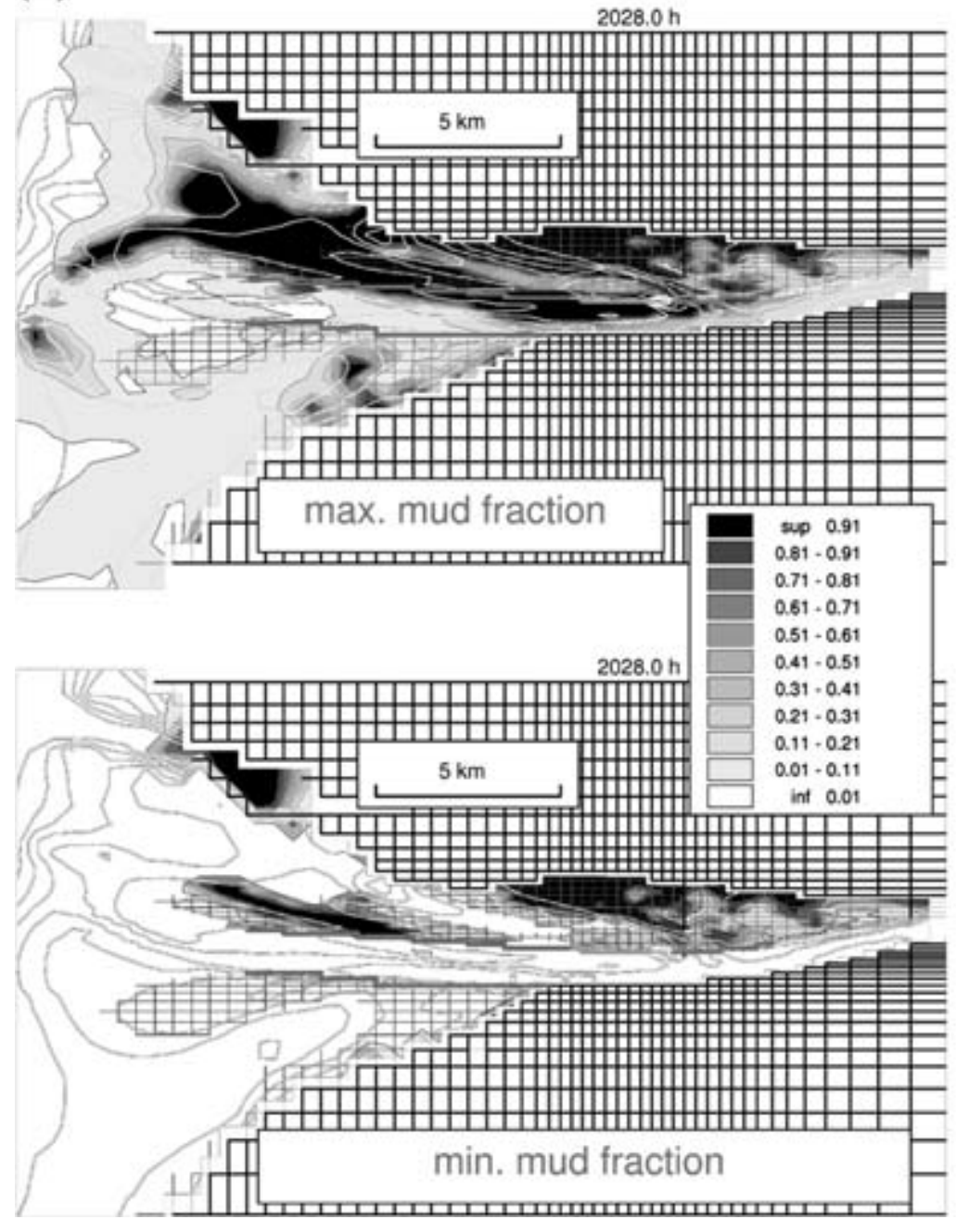

(b)

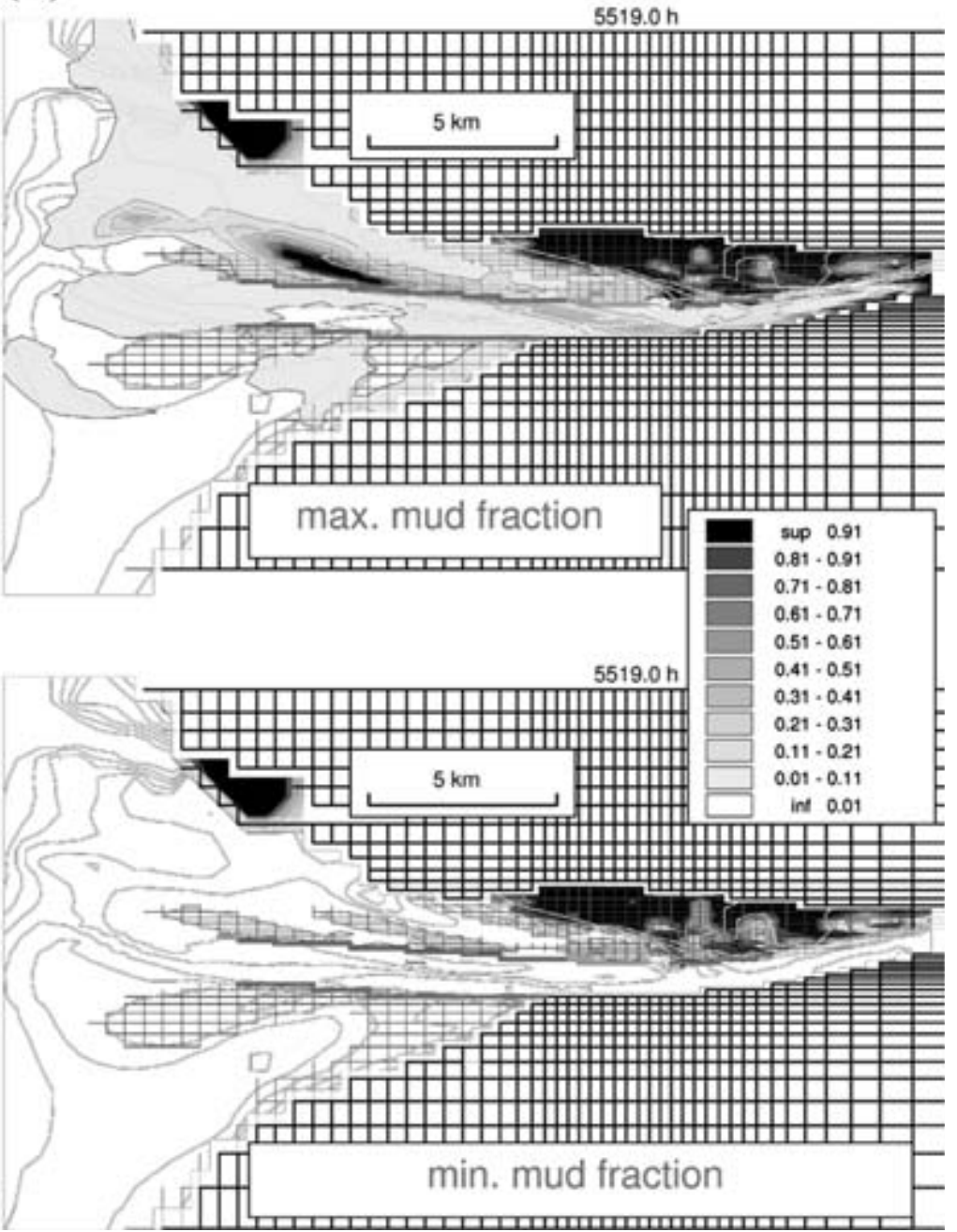

Fig. 6 Maximum and minimum mud fraction in the surficial layer (upper $2 \mathrm{~mm}$ ) over a spring tide period for: (a) high river discharge ( 2200 m3 s-1), (b) low river discharge ( $200 \mathrm{~m} 3 \mathrm{~s}-1)$ 
(a)

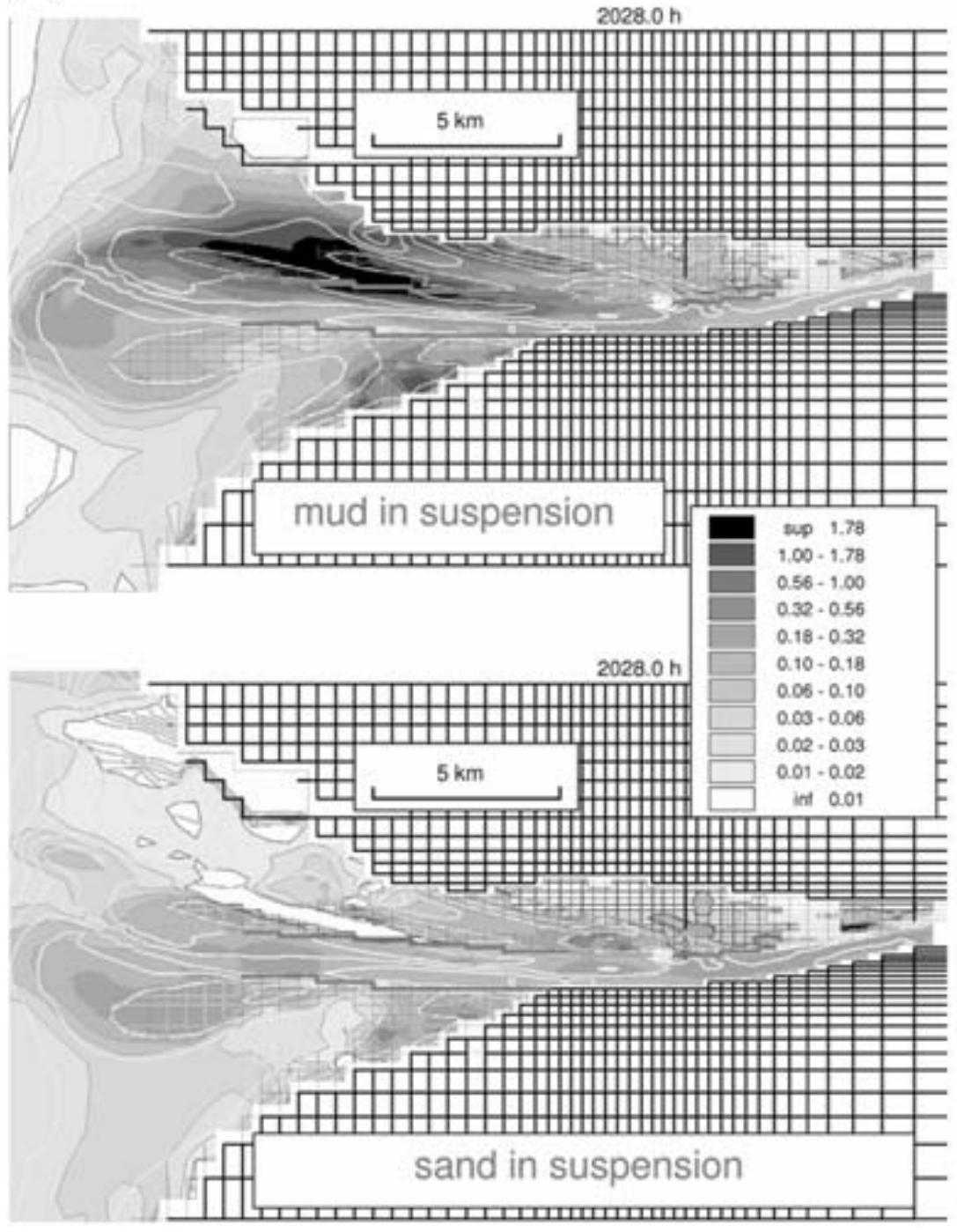

(b)

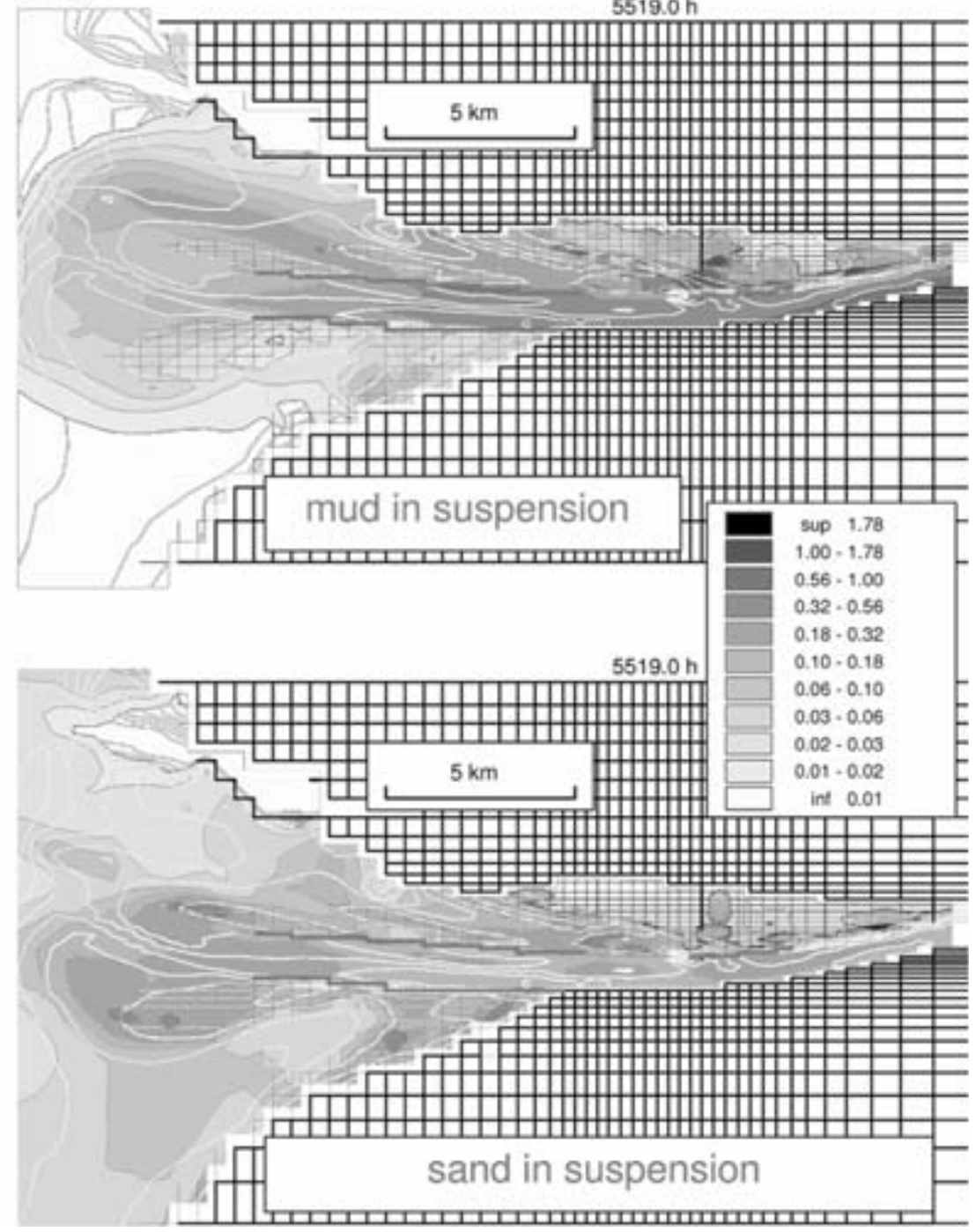


Fig. 7 Maximum concentrations (in $\mathrm{kg} \mathrm{m}-3$ ) of mud and sand in suspension in the bottom layer (of the water column) during a spring tide period: (a) for high river discharge $(\sim 2,200 \mathrm{~m} 3 \mathrm{~s}-1)$, (b) for low water discharge ( 200 m3 s-1). 

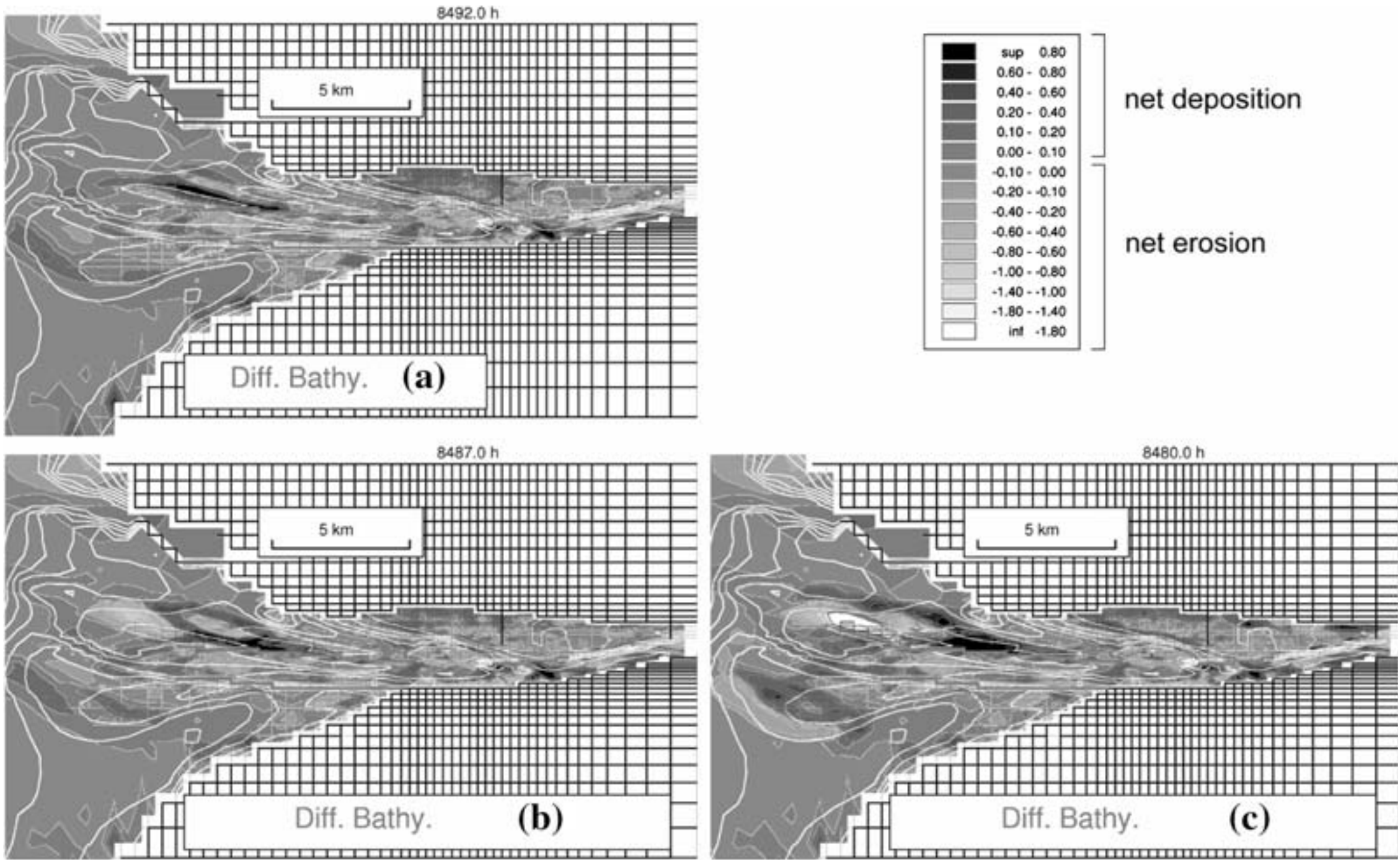

Fig. 8 Bathymetric variations over a 1-year period when the hydrodynamic forcing is: (a) tide only, (b) tide + wind + waves, (c) tide + wind + waves without morphodynamic updating. 